\title{
The prevalence of personality disorders in nurses: role of the workplace environment
}

\author{
Sahar Mirbaha', Parvin Kashani ${ }^{2}$, Ali Arhami Dolatabadi ${ }^{1}$, Afshin Amini ${ }^{1}$, Farahnaz Meschi ${ }^{3}$, Alireza \\ Baratloo $^{4 *}$
}

'Department of Emergency Medicine, Imam Hosein Hospital, Shahid Beheshti University of Medical Sciences, Tehran, Iran 2Department of Emergency Medicine, Loghman Hakim Hospital, Shahid Beheshti University of Medical Sciences, Tehran, Iran ${ }^{3}$ Department of Clinical Psychology, Karaj Branch Islamic Azad University, Alborz, Iran

${ }^{4}$ Department of Emergency Medicine, Sina Hospital, Tehran University of Medical Sciences, Tehran, Iran

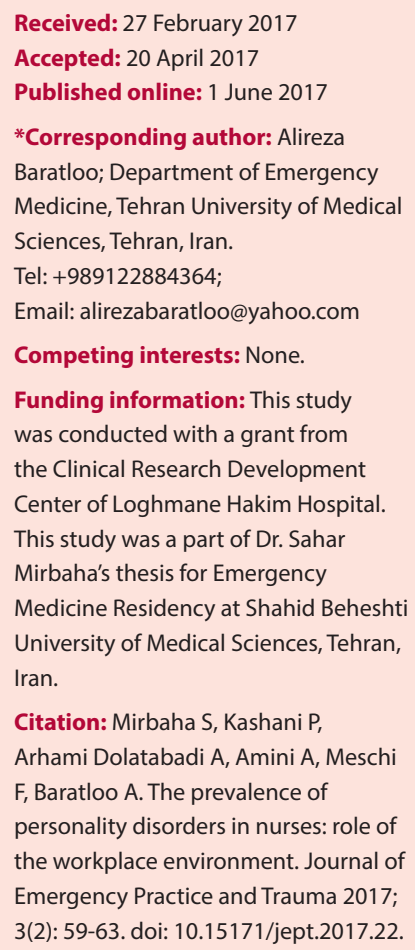

\begin{abstract}
Objective: Personality disorder is a multi-factorial condition in which workplace stress plays a significant role. This study was undertaken due to scarcity of information regarding the role of workplace stress which can cause personality disorder among nurses. We aimed to evaluate the prevalence of personality disorders in nurses working in different hospital departments and assess factors affecting its onset.

Methods: In this cross-sectional study the personality disorders of nurses working in various hospital departments were evaluated based on Minnesota Multiphasic Personality Inventory-2 (MMPI-2) test. After the completion of questionnaires, data were entered to MMPI-2 test's special software and the final result was interpreted based on the opinion of a clinical psychologist. Finally, multivariate logistic regression model was used to assess the independent effect of the mentioned factors on prevalence of personality disorders in nurses.

Results: We gathered data from 2 groups of participants $(n=206)$. These groups included nurses in emergency departments and nurses in other hospital units. The mean of age was 32.5 \pm 6.9 years. Overall, $54.3 \%(n=38)$ of non-emergency nurses and $45.7 \%(n=32)$ of emergency nurses showed symptoms of personality disorders respectively. Multivariate logistic regression analysis showed that history of a serious accident or trauma increased the odds of detecting personality disorders up to 3.8 times (odds ratio $[\mathrm{OR}]=3.84 ; 95 \% \mathrm{Cl}: 1.33-11.06 ; P=0.01$ ). In addition, an unpleasant incident in the past year increased it up to 2.2 times $(O R=2.23 ; 95 \% \mathrm{Cl}$ : $1.18-4.22 ; P=0.01$ ) in both groups.

Conclusion: The present study showed that there was no significant difference between emergency departments and other units of hospitals regarding the prevalence of personality disorders among nurses. Overall, somatization, hysteria, and pollyannaish were the most common personality disorders among the studied population.

Keywords: Personality disorders, Burnout, Professional, Workplace, Nurses
\end{abstract}

\section{Introduction}

The personality characteristics of each person play an important role in their manner of working and efficacy in their workplace. The stress and tension of workplace is one of the most important causes of psychological illnesses. Evidence shows that one fourth of the employed population have experienced some kind of job-related behavioral disorders (1). Benign and stimulant stress can cause enhancement in job performances, but harmful stress can destroy the talent of people in doing their tasks at their workplace (2). In the nursing career, nurses experience stressful events and intense mental pressure due to many interactions and the responsibilities that they have in the health care team. A systematic review showed a $26 \%-35 \%$ prevalence of personality and psychological disorders among emergency department (ED) nurses due to their job $(3,4)$. These disorders not only affect the personnel's health, but also decrease their competence and the quality of services they provide (5). On the other hand, the proper performance of personnel plays a major role in decreasing the burden caused by accidents and diseases. Thus, increasing patient satisfaction $(6,7)$.

Previous studies have reported the effect of work place in prevalence of psychological disorders in nurses. Personal, family-related, and social factors all exert an effect on the prevalence of these disorders $(8,9)$. Therefore, personality disorder is a multi-factorial condition in which stress of workplace, exhaustion of staff and personal and social factors should be studied simultaneously. Although numerous studies are available in the field of personality 
disorders caused by workplace stress, lack of such information in Iran reveals the need for a study in this field. Therefore, the present study was undertaken to evaluate the prevalence of personality disorders among nurses working in different hospital departments and assess factors affecting their incidence.

\section{Methods}

This cross-sectional study was undertaken among nurses working in EDs and other hospital units in three educational hospitals in Tehran, Iran.

We used a modified version of Minnesota Multiphasic Personality Inventory-2 (MMPI-2) test containing 71 questions to assess personality disorders. MMPI-2 is a standard questionnaire for gathering a wide range of selfdescribed characteristics. This inventory, representing a quantitative index of individuals' emotional adaptability, shows the attitude of participants regarding their personality traits (10). MMPI test is the most famous and widely used personality questionnaire that has been developed as an objective tool in the diagnosis of mental disorders. This test is a self-evaluation questionnaire with "yes" or "no" answers and has 3 validity scales and 10 clinical scales. Validity scales provide information regarding the subject's approach to the test, while the 10 primary clinical scales are used in the diagnosis of mental disorders. The most valuable use of MMPI- 2 is in screening abnormal people generally and determining the severity of the problem specifically (11). Diagnostic layers and scales of MMPI-2 include hypochondriasis, depression, hysteria, psychopathic deviate, masculinity/femininity, paranoia, psychasthenia, schizophrenia, hypomania, and social introversion. To increase the clinical benefit of MMPI, three validity scales are present including lie detection scale, infrequency, and defensiveness as correction or inhibition scales.

The study population consisted of nurses working in hospital departments (emergency and non-emergency wards). The sample was chosen based on simple random technique. In this regard, a list of nurses was prepared and participants were selected randomly. We excluded nurses who did not sign the consent form as well as incomplete or invalid questionnaires based on MMPI-2 test. Demographic data and MMPI-2 test were included in a questionnaire and distributed among the studied population.

Sample size was estimated to be 206 nurses based on $26 \%$ prevalence of personality disorders (3), $\alpha=0.05$, and $6 \%$. However, 5 cases were excluded due to the exclusion criteria. Thus, analyses were done on 102 emergency nurses and 99 nurses from other units. After questionnaire completion, data were entered to MMPI-2 test's special software and the final result was interpreted based on the opinion of a clinical psychologist. Data were analyzed via STATA 11.0 statistical software and the prevalence of personality disorders was reported as frequency and percentage. We used chi-squared, Fisher exact, and Mann-Whitney tests to assess the relationship of baseline and demographic factors among nurses. Finally, multivariate logistic regression model was used to assess the independent effect of the mentioned factors on the prevalence of personality disorders in nurses. In all analyses, $P<0.05$ was considered as statistically significant.

\section{Results}

Totally, 201 questionnaires were analyzed. We excluded 5 questionnaires as they were not valid based on MMPI-2 scale. All participants were female with a mean age of 32.5 \pm 6.9 years (range: $23-54$ years). Most participants were married (58.2\%) and 199 (99.0\%) had an undergraduate degree. $99(49.25 \%)$ participants worked in non-emergency departments (non-ED), and 102 (50.75\%) worked in ED. Table 1 reports the relationship of demographic and baseline factors of the studied population with personality disorders. There was no significant difference between the 2 groups regarding the prevalence of personality disorders. Overall, 70 (34.8\%) nurses showed symptoms of personality disorders in which 38 (54.3\%) of them worked in non-ED and $32(45.7 \%)$ worked in $\mathrm{ED}(P=0.30)$ (Figure 1). We observed 79 disorders. Five participants had 2, and 2 participants had 3 personality disorders. The most common personality disorder was somatization with 20 (10.0\%) cases. Among these cases, 11 (55.0\%) worked in non-ED and 9 (45\%) worked in ED. This was followed by hysteria with $8.0 \%$ prevalence $(33.3 \%$ in non-ED vs. $66.7 \%$ in ED), pollyannaish with $5.6 \%$ (55.0\% non-ED vs. $45.0 \%$ ED), and depression with $3.5 \%$ (57.1\% non-ED vs. $42.9 \%$ $\mathrm{ED})$. The distribution of these disorders was not related to the department they worked in $(P=0.89)$.

Table 1 shows the relationship between demographic and baseline factors of the studied population with personality disorders. Among the mentioned factors only an unpleasant incident in the past year $(P=0.01)$ and history of serious accident or trauma $(P=0.007)$ had a significant correlation with prevalence of personality disorders. In this regard, 58 nurses reported a serious unpleasant incident, $48.3 \%$ of which had personality disorders. On the other hand, only $29.4 \%$ of those who had not experienced this were diagnosed with these disorders. History of accident was present in 17 cases, $64.7 \%$ of which had personality disorders, compared to $32.1 \%$ prevalence in those without this experience.

Multivariate logistic regression analysis showed that history of serious accident or trauma increased the odds of detecting personality disorders up to 3.8 times (odds ratio $[\mathrm{OR}]=3.84 ; 95 \% \mathrm{CI}: 1.33-11.06 ; P=0.01$ ) and an unpleasant incident in the past year increased it up to 2.2 times $(\mathrm{OR}=2.23$; 95\%CI: $1.18-4.22 ; P=0.01)$ (Table 2).

\section{Discussion}

No difference was found between ED nurses and those who worked in other departments regarding the prevalence of personality disorders. This study showed 
Table 1. The relationship of demographic and baseline factors of the studied population with personality disorders

\begin{tabular}{|c|c|c|c|}
\hline \multirow{2}{*}{ Variable } & \multicolumn{2}{|c|}{ Personality disorders } & \multirow{2}{*}{$P$} \\
\hline & Absent & Present & \\
\hline Age (mean $\pm \mathrm{SD})$ & $32.3 \pm 6.3$ & $33.0 \pm 8.0$ & 0.50 \\
\hline \multicolumn{4}{|l|}{ Marital status } \\
\hline Single & $53(64.6)$ & $29(35.4)$ & $0.95^{*}$ \\
\hline Married & $77(65.8)$ & $40(34.2)$ & \\
\hline Divorced & $1(50.0)$ & $1(50.0)$ & \\
\hline \multicolumn{4}{|l|}{ Educational level } \\
\hline Undergraduate & $130(65.3)$ & $69(34.7)$ & $0.99^{*}$ \\
\hline Masters & $1(50.0)$ & $1(50.0)$ & \\
\hline \multicolumn{4}{|l|}{ Occupation } \\
\hline Nurse & $120(67.0)$ & $59(33.0)$ & 0.32 \\
\hline Head-nurse & $5(50.0)$ & $5(50.0)$ & \\
\hline Supervisor & $6(50.0)$ & $6(50.0)$ & \\
\hline \multicolumn{4}{|l|}{ Employment type } \\
\hline Apprentices & $22(62.9)$ & $13(37.1)$ & 0.74 \\
\hline Contract & $15(68.2)$ & $7(31.8)$ & \\
\hline Fixed-term & $5(50.0)$ & $5(50.0)$ & \\
\hline Full-time & $89(66.4)$ & $45(33.6)$ & \\
\hline \multicolumn{4}{|l|}{ Also works in another center } \\
\hline No & $130(65.3)$ & $69(34.7)$ & $0.99^{*}$ \\
\hline Yes & $1(50.0)$ & $1(50.0)$ & \\
\hline \multicolumn{4}{|l|}{ Working shift type } \\
\hline Day & $12(52.2)$ & $11(47.8)$ & 0.13 \\
\hline Night & $8(50.0)$ & $8(50.0)$ & \\
\hline Variable & $111(68.5)$ & $51(31.5)$ & \\
\hline Mean working hours/month & $211.4 \pm 51.2$ & $202.1 \pm 34.6$ & 0.17 \\
\hline Mean working experience (y) & $5.0 \pm 4.6$ & $6.0 \pm 6.2$ & $0.94^{\#}$ \\
\hline \multicolumn{4}{|l|}{ Location of house in Tehran } \\
\hline North & $9(50.0)$ & $9(50.0)$ & 0.71 \\
\hline West & $38(67.9)$ & $18(32.1)$ & \\
\hline East & $37(64.4)$ & $14(32.6)$ & \\
\hline Center & $29(67.4)$ & $14(32.6)$ & \\
\hline South & $18(66.7)$ & $9(33.3)$ & \\
\hline \multicolumn{4}{|l|}{ Income (dollars) } \\
\hline $270-420$ & $39(60.9)$ & $25(39.1)$ & $0.39^{\#}$ \\
\hline$>420$ & $92(67.2)$ & $45(32.8)$ & \\
\hline \multicolumn{4}{|c|}{ Sole breadwinner of the household } \\
\hline No & $121(64.4)$ & $67(35.6)$ & $0.55^{*}$ \\
\hline Yes & $10(76.9)$ & $3(23.1)$ & \\
\hline \multicolumn{4}{|l|}{ History of illness } \\
\hline No & $114(65.1)$ & $61(34.9)$ & 0.98 \\
\hline Yes & $17(50.3)$ & $9(49.7)$ & \\
\hline \multicolumn{4}{|l|}{ History of drug use } \\
\hline No & $115(65.3)$ & $61(34.7)$ & 0.90 \\
\hline Yes & $16(64.0)$ & $9(36.0)$ & \\
\hline \multicolumn{4}{|c|}{ History of mental disorders in family } \\
\hline No & $126(66.0)$ & $65(34.0)$ & 0.32 \\
\hline Yes & $5(50.0)$ & $5(50.0)$ & \\
\hline \multicolumn{4}{|l|}{ A serious unpleasant incident } \\
\hline No & $101(70.6)$ & $42(29.4)$ & 0.01 \\
\hline Yes & $30(51.7)$ & $28(48.3)$ & \\
\hline \multicolumn{4}{|l|}{ History of accident } \\
\hline No & $125(67.9)$ & $59(32.1)$ & 0.007 \\
\hline Yes & $6(35.3)$ & $11(64.7)$ & \\
\hline
\end{tabular}

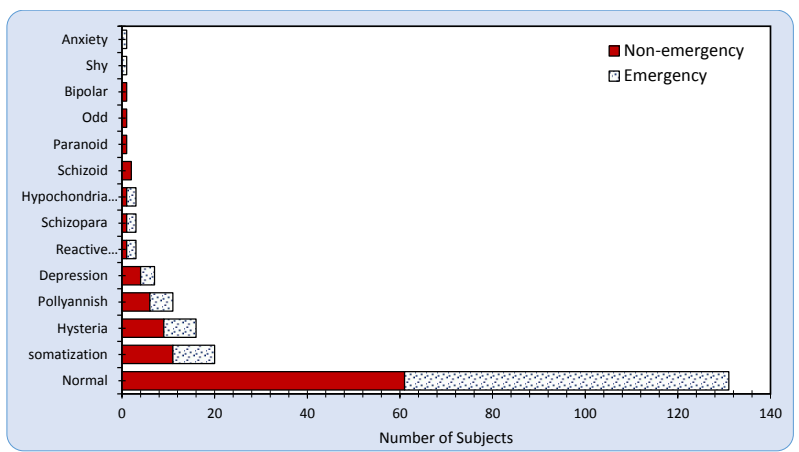

Figure 1. Distribution of the frequency of personality disorders in the studied population based on the department they worked in.

that somatization, hysteria, and pollyannaish were the most common personality disorders among nurses in emergency departments and other departments in the studied hospitals. History of serious accident or trauma and an unpleasant incident happening in the past year were the only effective factors causing personality disorders in the studied population.

The prevalence of personality disorders in the general population has been reported to be $4.4 \%-10.6 \%$ (12-14), which might be related to the role of workplace stress in the onset of personality disorders. Nevertheless, some personality disorders remain hidden and symptoms are only revealed when the person is under workplace stress. Therefore, workplace stress may only be a trigger for manifestation of the hidden disorders' symptoms, and not the cause. This might be the reason that in the present study, the prevalence of personality disorders was not significantly different between ED nurses (highly stressful workplace) and those working in other departments (less stressful workplace).

Mealer et al reported 18\% more anxiety and 11\% higher depression rates among intensive care unit (ICU) nurses compared to the general population (29\% more in total) (15). In our study, the prevalence of anxiety and depression was $0.5 \%$ and $3.5 \%$ respectively. This difference might be due to the studied population. In this study, nurses were selected from different hospital departments, while in the study by Mealer et al only ICU nurses were evaluated. In the ICU, death and dangerous conditions are more prevalent compared to other departments. Exposure of nurses to death scenes and dying patients for a long time can take a toll on their mental wellbeing. This is supported by the findings of a study that showed emotional responses and psychophysiologic outcomes were more severe in nurses who had witnessed death and serious injuries in comparison with others. Therefore, individuals in this group were more prone to post-traumatic stress disorders (16).

We did not observe a correlation between the departments in which the nurses worked and the presence of personality disorders. In line with this study, Escribà-Agüir et al also showed that there was no evidence that workplace and hardness of work negatively impact presentation of 
Table 2. The relationship of demographic and baseline factors of the studied population with personality disorders based on multivariate logistic regression analysis

\begin{tabular}{lccc}
\hline Variable & OR & $\mathbf{9 5 \%} \mathbf{C l}$ & $\boldsymbol{P}$ \\
\hline History of serious accident or trauma & 3.84 & $1.33-11.06$ & 0.01 \\
\hline Unpleasant incident in the past year & 2.23 & $1.18-4.22$ & 0.01 \\
\hline
\end{tabular}

Abbreviation: OR, Odds ratio.

burnout syndrome (2). However, Yang et al measured saliva cortisol and expressed that ED nurses had higher levels of cortisol and stress compared to nurses from other departments (17). However, we should note that high saliva cortisol and stress levels are not necessarily accompanied by higher prevalence of personality disorders. Therefore, we contend that ED nurses tolerate more stress but it does not increase the risk of having mental diseases (17). In other words, ED nurses' ability to adjust to stress might have prevented them from developing personality disorders and showing symptoms. Psychological flexibility is a factor affecting mental disorders (15). Presence of psychological flexibility results in a significant decrease in the prevalence of post-traumatic stress disorder, burnout syndrome, and symptoms of depression and anxiety. Therefore, flexibility is a defense mechanism that can increase the ability of nurses and other medical staff to adapt to workplace stresses. Since psychological flexibility can be acquired by training, programs to upgrade the skills of the treatment staff regarding psychological flexibility can decrease the symptoms of mental and personality disorders, and increase job satisfaction (15).

Environmental stressors are among the factors leading to mental and personality disorders $(18,19)$. The findings of this study also showed that history of serious accident or trauma and an unpleasant incident happening in the past year were independent factors that had an effect on the onset of personality disorders in nurses. Therefore, jobrelated personality disorder is a multi-factorial syndrome which is affected by both workplace and personal life stresses.

One of the limitations of this study was its small sample size. Although the number of cases required was calculated to be 206 nurses but only 201 questionnaires were analyzed as 5 questionnaires were invalid. Notwithstanding, the power of the study was calculated to be $96 \%$, which guarantees the validity of the findings. The nature of evaluating personality disorders is another limitation of this study. In most cases, personality disorders were not a single problem and several diagnoses were made for an individual. Therefore, it is possible that the reported percentages may be different from reality to some extent. In addition, the opinion of the psychologist who made the diagnosis also affected the calculated percentages.

\section{Conclusion}

The present study showed that somatization, hysteria, and pollyannaish were the most common personality disorders among the studied nurses. History of serious accident or trauma and an unpleasant event happening in the past year were the only effective factors in the onset of personality disorders among the studied nurses. No difference was found between ED nurses and those who worked in other departments regarding the prevalence of personality disorders.

\section{Ethical issues}

The protocol of the study was approved by the ethical committee of Shahid Beheshti University of Medical Sciences. Written informed consent was obtained from all nurses. All researchers adhered to the principles of Helsinki declaration throughout the study.

\section{Acknowledgments}

We would like to express our special thanks to Ms. Mahnaz Nikpeyma who especially helped us in performing this study.

\section{Authors' contributions}

All authors have contributed to drafting/revising the manuscript, study concept, or design, as well as data collection and interpretation.

\section{References}

1. Kessler RC, Demler O, Frank RG, Olfson M, Pincus HA, Walters EE, et al. Prevalence and treatment of mental disorders, 1990 to 2003. N Engl J Med 2005; 352(24): 251523. doi: 10.1056/NEJMsa043266.

2. Escribà-Agüir V, Martín-Baena D, Pérez-Hoyos S. Psychosocial work environment and burnout among emergency medical and nursing staff. Int Arch Occup Environ Health 2006; 80(2): 127-33. doi: 10.1007/s00420006-0110-y.

3. Adriaenssens J, De Gucht V, Maes S. Determinants and prevalence of burnout in emergency nurses: a systematic review of 25 years of research. Int J Nurs Stud 2015; 52(2): 649-61. doi: 10.1016/j.ijnurstu.2014.11.004.

4. Forouzanfar MM, Alitaleshi H, Hashemi B, Baratloo A, Motamedi M, Majidi A, et al. Emergency nurses' job satisfaction and its determinants in the hospitals of Shahid Beheshti University of Medical Sciences. Advances in Nursing \& Midwifery 2013; 23(80): 10-14. [In Persian].

5. Visser MR, Smets EM, Oort FJ, De Haes HC. Stress, satisfaction and burnout among Dutch medical specialists. CMAJ 2003; 168(3): 271-5.

6. Spence Laschinger HK, Leiter MP. The impact of nursing work environments on patient safety outcomes: The mediating role of burnout engagement. J Nurs Adm 2006; 36(5): 259-67.

7. Baratloo A, Maleki M. Iranian emergency department overcrowding. Journal of Emergency Practice and Trauma 2015; 1(2): 39.

8. Garrosa E, Moreno-Jimenez B, Liang Y, González JL. The relationship between socio-demographic variables, job stressors, burnout, and hardy personality in nurses: an exploratory study. Int J Nurs Stud 2008; 45(3): 418-27. doi: 10.1016/j.ijnurstu.2006.09.003.

9. Garrosa E, Rainho C, Moreno-Jimenez B, Monteiro MJ. The relationship between job stressors, hardy personality, coping resources and burnout in a sample of nurses: a correlational study at two time points. Int J Nurs Stud 2010; 
47(2): 205-15. doi: 10.1016/j.ijnurstu.2009.05.014.

10. Butcher JN, Dahlstrom WG, Graham JR, Tellegen A, Kaemmer B. Manual for the restandardized Minnesota Multiphasic Personality Inventory: MMPI-2. Minneapolis: University of Minnesota Press; 1989.

11. Temple R. Minnesota Multiphasic Personality Inventory. Encyclopedia of Clinical Neuropsychology. Springer; 2011. p. 1629-32.

12. Lenzenweger MF. Epidemiology of Personality Disorders. Psychiatr Clin North Am 2008; 31(3): 395-403. doi: 10.1016/j.psc.2008.03.003.

13. Grant BF, Chou SP, Goldstein RB, Huang B, Stinson FS, Saha TD, et al. Prevalence, correlates, disability, and comorbidity of DSM-IV borderline personality disorder: results from the Wave 2 National Epidemiologic Survey on Alcohol and Related Conditions. J Clin Psychiatry 2008; 69(4): 533-45.

14. Coid J, Yang M, Tyrer P, Roberts A, Ullrich S. Prevalence and correlates of personality disorder in Great Britain. The Br J Psychiatry 2006; 188(5): 423-31. doi: 10.1192/ bjp.188.5.423.

15. Mealer M, Jones J, Newman J, McFann KK, Rothbaum B,
Moss M. The presence of resilience is associated with a healthier psychological profile in intensive care unit (ICU) nurses: results of a national survey. Int J Nurs Stud 2012; 49(3): 292-9. doi: 10.1016/j.ijnurstu.2011.09.015.

16. Carson MA, Paulus LA, Lasko NB, Metzger LJ, Wolfe J, Orr SP, et al. Psychophysiologic assessment of posttraumatic stress disorder in Vietnam nurse veterans who witnessed injury or death. Consult Clin Psychol 2000; 68(5): 890-7.

17. Yang Y, Koh D, Ng V, Lee FC, Chan G, Dong F, et al. Salivary cortisol levels and work-related stress among emergency department nurses. J Occup Environ Med 2001; 43(12): 1011-8.

18. Xue C, Ge Y, Tang B, Liu Y, Kang P, Wang M, et al. A metaanalysis of risk factors for combat-related PTSD among military personnel and veterans. PloS One 2015; 10(3): e0120270. doi: 10.1371/journal.pone.0120270.

19. Jahn DR, Poindexter EK, Cukrowicz KC. Personality disorder traits, risk factors, and suicide ideation among older adults. Int Psychogeriatr 2015; 27(11): 1785-94. doi: $10.1017 /$ S1041610215000174. 